\title{
CONTRIBUIÇÕES DO PET REDE DE ATENÇÃO PSICOSSOCIAL NA FORMAÇÃO ACADÊMICA NO CURSO DE CIÊNCIAS BIOLÓGICAS
}

Apresentação: Relato de Experiência

Rosália Rodrigues da Costa Silva ${ }^{1}$; Fernanda Jorge Guimarães ${ }^{2}$; Jaqueline Galdino Albuquerque Perrelli³ ${ }^{3}$ Joseane Pulcina Barros de Andrade ${ }^{4}$

\section{Introdução}

A prevenção do uso de álcool, crack e outras drogas na escola é considerada uma intervenção importante e indispensável. Para tanto, é fundamental o uso de teorias construtivas que possam ser usadas em diversas abordagens e atividades. Além disso, devem ser promovidas abordagens de outros temas relacionados ao abuso de álcool e outras drogas, como família, vínculos afetivos, sexualidade, que instigam a curiosidade dos adolescentes e da comunidade escolar. Para realizar tais ações, pode-se utilizar de programas de aprendizagem tutorial, como o Programa de Educação pelo Trabalho para a Saúde/ Redes de Atenção à Saúde (PET- Saúde/ Redes). Trata-se de um programa do Ministério da Saúde, que objetiva a integração ensino- serviço- comunidade, por meio da formação de grupos de aprendizagem tutorial. O Programa apoiou diversos projetos relacionados as Redes de Atenção à Saúde, como: Rede de Cuidados à Pessoa com Deficiência; Rede de Atenção a Doenças Crônicas; Rede Cegonha; Rede de Atenção às Urgências e Emergências; Rede de Atenção Psicossocial.

A partir do exposto, o trabalho tem como objetivo descrever as contribuições do PET SaúdeRede de Atenção Psicossocial na formação acadêmica no curso de Ciências Biológicas.

\section{Relato de Experiência}

O problema do abuso de substâncias psicoativas por jovens chama atenção para a necessidade de abordá-lo no âmbito escolar. Para tanto, engloba-se a teoria da aprendizagem significativa, a qual propõe que os conhecimentos prévios dos alunos sejam valorizados, para que possam construir estruturas mentais utilizando, como meio, diversos instrumentos didáticos, como mapas conceituais, por exemplo (PELIZZARI ; KRIEGEL; BARON, et al, 2002).

Dessa forma, o grupo PET Saúde- Rede de Atenção Psicossocial foi composto por uma

\footnotetext{
${ }^{1}$ Ciências Biológicas, CAV-UFPE, roebiel_23@hotmail.com

${ }^{2}$ Núcleo de Enfermagem, CAV-UFPE, ferjorgui@hotmail.com

${ }^{3}$ Núcleo de Enfermagem, CAV-UFPE, jaquelinealbuquerque@hotmail.com

${ }^{4}$ Psicologa e preceptora, CAV- UFPE, a_josiane@hotmail.com
} 
equipe com professores tutores, preceptora, alunos bolsistas e voluntários dos cursos de Graduação em Enfermagem, Saúde Coletiva e Ciências Biológicas do Centro Acadêmico de Vitória da Universidade Federal de Pernambuco (CAV- UFPE), no período de 2013 a 2015. O projeto desenvolveu-se em escolas públicas no município da Vitória de Santo Antão (PE) e teve como principal objetivo a prevenção ao abuso de substâncias com os adolescentes. Para fundamentar as ações, utilizou-se a Teoria Freiriana. Desenvolveram-se oficinas com os estudantes, as quais eram realizadas semanalmente. Em cada oficina havia três momentos: acolhimento, discussão do tema e avaliação. Utilizaram-se vídeos, colagem e pintura para a discussão dos temas.

As contribuições para a formação acadêmica da licencianda em Ciências Biológicas envolveu a aquisição de conhecimentos e trocas de saberes com os graduandos de outros cursos, o que promoveu a interdisciplinaridade entre os componentes do grupo e, dessa forma, foi conduzida às salas de aula de todas as escolas. As ações realizadas com discussões sobre diversos temas relacionados ao abuso de substâncias, diálogos com rodas de conversa, trabalhos em grupo, apresentações, deixou evidente a importância da informação e do diálogo, ao esclarecer dúvidas e, por conseguinte contribuiu para a promoção da saúde e prevenção do abuso de substâncias psicoativas. Dessa forma, a troca de vivências e experiências gerou uma grande contribuição conjunta de ambos os lados: graduandos, alunos e comunidade escolar no processo de ensinoaprendizagem.

Imagem 1: Oficina. Fonte: arquivo projeto

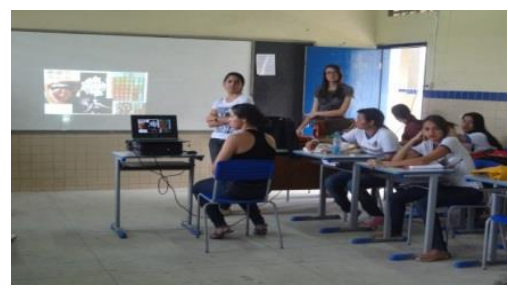

\section{Considerações finais}

As várias práticas vivenciadas durante todo o projeto contribuíram de forma efetiva e enriquecedora na formação do profissional licenciando em Ciências Biológicas, uma vez que as ações produziram troca de conhecimentos muito valiosa entre discentes de diferentes cursos de Graduação, e alunos de diferentes idades e instituições, o que revelou a importância da interdisciplinaridade no contexto profissional, e escolar no processo de ensino- aprendizagem. Além de, também, vivenciar na prática como o licenciado pode trabalhar temas transversais relacionados a esses problemas na escola e em diversos campos.

\section{Referências}

PELIZZARI, A.; KRIEGEL, M. L.; BARON, M. P.; et al. Teoria da Aprendizagem significativa 
Segundo Ausubel. Rev. PEC, Curitiba, v.2, n.1, p.37-42, jul.2002. Disponível em: <http://portaldoprofessor.mec.gov.br/> Acesso em: 28 set, 2016. 